\title{
Transmembrane Potential of Red Blood Cells Under Low Ionic Strength Conditions
}

\author{
Daniel Moersdorfa, Stephane Egee ${ }^{b, d}$ Claudia Hahn ${ }^{a}$ Benjamin Hanfa \\ Clive Ellory ${ }^{c}$ Serge Thomas ${ }^{b}$ Ingolf Bernhardt ${ }^{a}$
}

aLaboratory of Biophysics, Faculty of Natural and Technical Sciences III, Saarland University, Building A2 4, 66123 Saarbruecken, Germany; bUMR 7150 CNRS-UPMC, Station Biologique, Place Georges Teissier, BP 74, 29682 Roscoff Cedex, France; 'Department of Physiology, Anatomy \& Genetics, University of Oxford, Parks Road, Oxford OX1 3PT, UK; 'd contributed equally and thus share first authorship

\section{Key Words}

Red blood cells • Transmembrane potential • Low ionic strength $\bullet$ CCCP $\bullet \operatorname{DiBAC}_{4}(3) \cdot$ Flow cytometry

\begin{abstract}
Background/Aims: In a variety of investigations described in the literature it was not clear to what extent the transmembrane potential red blood cells (RBCs) was changed after the cells have been transferred into low ionic strength (LIS) solutions. Another open question was to find out how fast the transmembrane potential of RBCs in LIS solution will change and which final new equilibrium value will be reached. Methods: The transmembrane potential of human and bovine RBCs was investigated using the potential-sensitive fluorescent dye $\operatorname{DIBAC}_{4}(3)$ (bis(1,3-dibutylbarbituric acid) trimethine oxonol) as well as the CCCP (carbonylcyanide-mchlorophenylhydrazone) method. Results: Under physiological conditions the transmembrane potential was about $-10 \mathrm{mV}$ in agreement with literature data. However, when the RBCs were transferred into an isosmotic low ionic strength medium containing sucrose the transmembrane potential increased to $+73 \mathrm{mV}$ and $+81 \mathrm{mV}$ for human and bovine RBCs, respectively. In case of human RBCs it continuously decreased reaching finally an equilibrium state of $-10 \mathrm{mV}$ again after $30-60 \mathrm{~min}$. For bovine RBCs the transmembrane potential declined more slowly reaching a value of $+72 \mathrm{mV}$ after 30 min. Conclusions: Investigations of parameters of RBCs depending on transmembrane potential cannot be performed with human RBCs in LIS media.
\end{abstract}

Copyright (C) 2013 S. Karger AG, Basel

\section{Introduction}

For cation transport studies of human RBCs, it has been known for some decades that, following inhibition of mediated transport systems with selective inhibitors, the residual 
unidirectional $\mathrm{Na}^{+}$and $\mathrm{K}^{+}$fluxes (influxes and effluxes) as well as net salt efflux of human RBCs are significantly enhanced in low ionic strength (LIS) media when the extracellular $\mathrm{NaCl}$ is replaced by sucrose [1]. This behaviour is known as the LIS effect in the literature and has been attributed to a variety of different mechanisms [2-7]. In our previous investigations we were able to demonstrate that the LIS effect can be easily ascribed to a $\mathrm{K}^{+}\left(\mathrm{Na}^{+}\right) / \mathrm{H}^{+}$exchanger. This explanation is based on findings that the residual $\mathrm{K}^{+}$transport does not depend on the transmembrane potential [8-10], theoretical calculations [11], and a demonstration of a $1: 1$ exchange of $\mathrm{K}^{+}$and $\mathrm{H}^{+}$under LIS conditions [12]. In addition, the non-selective, voltagedependent cation (NSVDC) channel has to be taken into consideration [13-15]. Donlon and Rothstein [6] decreased the extracellular ionic strength to a very low level and described the increase of the net $\mathrm{K}^{+}$loss as a triphasic response (curve with two inflection points). Starting at physiological ionic strength and reducing it, the $\mathrm{K}^{+}\left(\mathrm{Na}^{+}\right) / \mathrm{H}^{+}$exchanger is exclusively of importance to make a substantial contribution to the increase of the $\mathrm{K}^{+}$loss, at lower ionic strengths the NSVDC channel is additionally of importance, and at very low ionic strengths it seems reasonable to propose the start of an electrical break-down of the membrane [16].

However, in all investigations of the LIS effect, it was not clear to what extent the transmembrane potential was changed after the RBCs have been transferred to LIS solutions. Of course one could estimate the value by simply assuming a Nernst equilibrium for chloride but this would be the case only if the permeability coefficient for $\mathrm{Cl}^{-}\left(\mathrm{P}_{\mathrm{Cl}}\right)$ is still much larger (e.g. 100 times) than the permeability coefficients for $\mathrm{K}^{+}$and $\mathrm{Na}^{+}\left(\mathrm{P}_{\text {Cat }}\right)$ in LIS medium. Assuming a change of this situation (e.g. leading to a ten times difference only), the peak transmembrane potential in LIS solution would be much lower (for calculations see [1]).

Another open question is to find out how fast this peak of the transmembrane potential of RBCs in LIS solution will change and which final new equilibrium value will be reached. For instance, in a series of investigations of the shape of RBCs depending on the transmembrane potential, Glaser [17] assumed that the new potential of the cells in LIS solution is constant for at least one hour (as long as $\mathrm{P}_{\mathrm{Cat}}$ does not increase in relation to $\mathrm{P}_{\mathrm{Cl}}$ ). In his model calculations, he called the situation c-state ( $\mathrm{Cl}^{-}$equilibrium state).

In the present study experiments have been carried out to solve both questions. The general idea of a relatively rapid change of the transmembrane potential of human RBCs in LIS solution after the maximum value is reached is based on earlier reports of our group describing continuous changes of the intracellular $\mathrm{pH}$ and significant $\mathrm{Cl}^{-}$loss of RBCs in LIS media [12]. In contrast, it has been found that bovine RBCs do not exhibit the normal LIS effect, i.e. an enhanced $\mathrm{K}^{+}$efflux in sucrose media [18]. In addition, it was shown that the change of the intracellular pH of bovine RBCs in LIS solution after the maximum is reached declines significantly lower compared to human RBCs [16]. Demonstrating the time course of the membrane potential changes is essential for understanding the relative contributions of discrete transporters to transmembrane cation transport in this condition, and will allow the relative importance of the $\mathrm{K}^{+}\left(\mathrm{Na}^{+}\right) / \mathrm{H}^{+}$exchanger (probably the NHE7 isoform), classically associated with intracellular organelles, to be established.

\section{Materials and Methods}

\section{Blood and solutions}

Human venous blood from healthy donors was obtained from the Institute of Clinical Haematology and Transfusion Medicine of Saarland University Hospital, Homburg (Germany) and Centre Hélio-Marin Perharidy, Roscoff (France). Citrate or EDTA were used as anticoagulants. Bovine blood was obtained from slaughterhouse "abattoir du Faou", Le Faou, France. Freshly drawn blood samples were stored at $4{ }^{\circ} \mathrm{C}$ and used within one day.

Blood was centrifuged at 2,000 g for $5 \mathrm{~min}$ at room temperature (RT) and the plasma and buffy coat was removed by aspiration. Subsequently, RBCs were washed 2 times in HEPES-buffered physiological solution (HPS) containing (mM): $\mathrm{NaCl} 145, \mathrm{KCl} 7.5$, glucose 10, HEPES 10, pH 7.4, under the same conditions. For CCCP measurements, cells are washed 3 times in unbuffered solution containing (mM) 
Moersdorf et al.: Transmembrane Potential of Red Blood Cells

$\mathrm{NaCl} 145, \mathrm{KCl} 7.5$ and kept as packed cells (98\% haematocrit) until experiment started. Finally, RBCs were washed once in the appropriate medium used for the experiment (buffered solutions for $\operatorname{DiBAC}_{4}(3)$ (bis $(1,3-$ dibutylbarbituric acid) trimethine oxonol) and unbuffered solutions for the CCCP (carbonylcyanide-mchlorophenylhydrazone) method, see below).

Measurement of the transmembrane potential using $\operatorname{DiBAC}_{4}(3)$

RBCs were loaded with the potential-sensitive fluorescent dye $\operatorname{DiBAC}_{4}(3)$. The cells were incubated with $250 \mathrm{nM}$ of the dye from a $25 \mathrm{mM}$ stock solution in dimethyl sulfoxide (DMSO) in $1 \mathrm{ml}$ HPS at a haematocrit of $0.2 \%$ for $30 \mathrm{~min}$ at RT in the dark. The cell suspension was directly used for measurements in HPS. If cells were measured in LIS media, the cell suspension was centrifuged $(20 \mathrm{~s}, 12,000 \mathrm{~g})$. Then the supernatant was replaced by a LIS medium containing $250 \mathrm{nM} \mathrm{DiBAC}_{4}(3)$. The LIS media contained (mM): sucrose 250 or $200, \mathrm{KCl} 7.5$, glucose 10, HEPES 10, pH 7.4.

The fluorescence measurements were carried out by flow cytometry (FACS Calibur and Cell Quest Pro software, Becton Dickinson Biosciences, Franklin Lakes, USA). Fluorescence was measured in the FL-1 channel at time $0,5,10,15$, and $30 \mathrm{~min}$ and analysed using the mean value of the relative fluorescence of 20,000 cells from each measurement. Time 0 means about $15 \mathrm{~s}$ after addition of LIS medium. The duration of one measurement was about $10-15 \mathrm{~s}$. For each experiment at least three different blood samples were used.

The calibration (for each experiment) was carried out with valinomycin $(1 \mu \mathrm{M}$, final concentration, dissolved in ethanol). However, a treatment with valinomycin in the presence of different extracellular $\mathrm{KCl}$ concentrations (replacement for $\mathrm{NaCl}$ ) results in negative transmembrane potentials if the extracellular solution contains $134 \mathrm{mM}$ or less $\mathrm{KCl}$ (assuming an intracellular KCl concentration of $134 \mathrm{mM} \mathrm{[19]).}$ Maximally, if the extracellular solution contains $150 \mathrm{mM} \mathrm{KCl}$ and $0 \mathrm{mM} \mathrm{NaCl}$, a transmembrane potential of $+10 \mathrm{mV}$ can be reached (an increasing transmembrane potential results in raising fluorescence intensity). Therefore, we were able to convert the measured fluorescence intensity of $\operatorname{DiBAC}_{4}(3)$ treated $\mathrm{RBCs}$ into a transmembrane potential only under physiological conditions. For low ionic strength conditions the CCCP method was used.

Measurement of the transmembrane potential using the CCCP method

Packed RBCs were injected into either an unbuffered physiological solution (high ionic strength, HIS) (mM): $\mathrm{NaCl} \mathrm{145,} \mathrm{KCl} \mathrm{7.5,} \mathrm{or} \mathrm{unbuffered} \mathrm{LIS} \mathrm{media} \mathrm{(mM):} \mathrm{sucrose} 250$ or 200, KCl 7.5. The haematocrit was about $4 \%, 200 \mu \mathrm{l}$ of packed cells were added to $4.8 \mathrm{ml}$ of solutions. In all experiments, solutions were supplemented with $20 \mu \mathrm{M}$ of the protonophore CCCP (final concentration, from a stock solution prepared in DMSO).

The transmembrane potential $\left(\mathrm{V}_{\mathrm{m}}\right)$ of RBCs was estimated by continuous monitoring of extracellular $\mathrm{pH}\left(\mathrm{pH}_{\text {out }}\right)$ in the presence of CCCP using a conventional $\mathrm{pH}$ electrode and calculated using the equation: $\mathrm{V}_{\mathrm{m}}$ $=61.5 \mathrm{mV} \times\left(\mathrm{pH}_{\text {in }}-\mathrm{pH}_{\text {out }}\right)$. Due to the high RBC buffer capacity, the intracellular $\mathrm{pH}\left(\mathrm{pH}_{\text {in }}\right)$ remains constant throughout the experiment. It was determined as the $\mathrm{pH}$ in the solution after the cells were lysed by addition of $200 \mu \mathrm{l}$ Triton X-100 (1\% v/v) in $2 \mathrm{M} \mathrm{NaCl}$ solution. This method has been widely used to determine the transmembrane potential of RBCs under various conditions including LIS solutions [20-23].

To prove the validity of the method, experiments were carried out using 4 different concentrations of extracellular KCl. Cells were permeabilized with $1 \mu \mathrm{M}$ valinomycin, under condition of anionic conductance inhibition using NS1652 (10 $\mu \mathrm{M})$ [22]. Hyperpolarization was measured and eventually plotted against exact values of extracellular potassium determined by flame photometry.

Reagents

All chemicals used (except $\operatorname{DiBAC}_{4}(3)$ ) were purchased from Sigma-Aldrich (Munich, Germany). $\mathrm{DiBAC}_{4}(3)$ was obtained from Molecular Probes (Eugene, USA).

\section{Statistical significance}

Data are presented as mean values \pm SD of at least 3 independent experiments carried out on blood of different donors. The significance of differences was tested by Student's $t$-test. The values were taken as significantly different when $\mathrm{p} \leq 0.05$. 


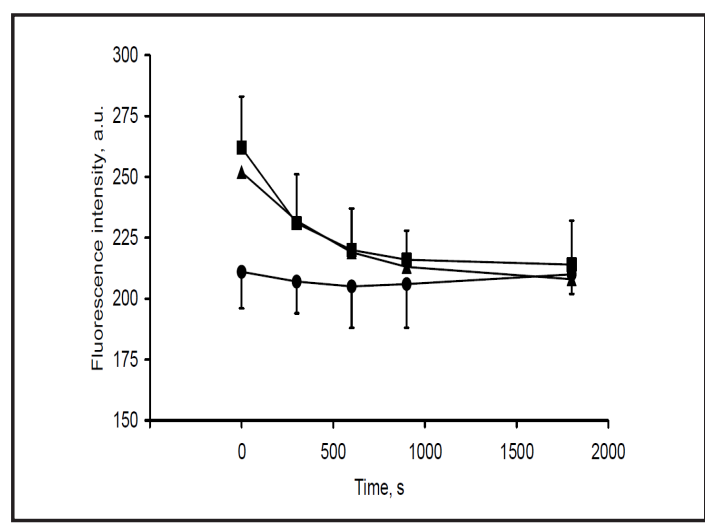

Fig. 1. Flow cytometric analysis of $\operatorname{DiBAC}_{4}(3)$ fluorescence intensity (arbitrary units) of human RBCs for transmembrane potential over a time interval of $30 \mathrm{~min}$ in physiological solution (0) as well as in low ionic strength solution containing 250 mM (ם) or $200 \mathrm{mM}(\boldsymbol{\Delta})$ sucrose. Error bars (not shown for $200 \mathrm{mM}$ data) represent mean values of at least 5 different blood samples \pm SD (with 20,000 cells per sample).

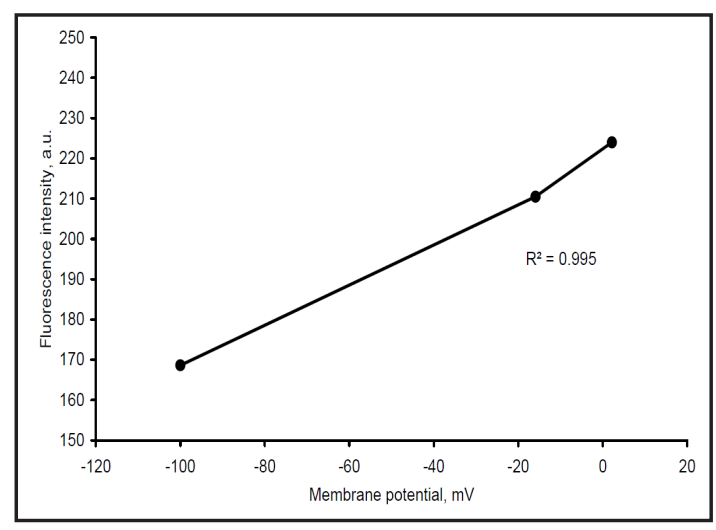

Fig. 2. Representative calibration curve for human RBCs to convert the fluorescence intensity of $\mathrm{DiBAC}_{4}(3)$ into the corresponding transmembrane potential. For each experiment (blood sample) a calibration curve was determined. For details see Materials and Methods section.

\section{Results}

Measurements of the transmembrane potential of human RBCs in physiological solution (HPS) using the potential-sensitive fluorescent dye $\operatorname{DiBAC}_{4}(3)$ resulted in a value of $-13.8 \pm$ $5.6 \mathrm{mV}(\mathrm{n}=6)$. It was constant over $30 \mathrm{~min}$. The corresponding fluorescence intensities can be seen in Fig. 1, the potential values were converted from calibration measurements using valinomycin at various extracellular $\mathrm{KCl}$ concentrations. One typical single calibration curve is presented in Fig. 2. The obtained value for the transmembrane potential is in agreement with literature data (e.g. [23-25]). When the RBCs are transferred into a LIS medium, the fluorescence intensity increased significantly and continuously declined back close to the value estimated for physiological solution in about $30 \mathrm{~min}$. This means that the transmembrane potential raised to positive values (much higher than $+10 \mathrm{mV}$, estimated from calibration with valinomycin) with a following continuous decrease. The isosmotic LIS medium contained $250 \mathrm{mM}$ sucrose. However, under this condition, it is known that the RBCs shrink [9]. To avoid a possible volume effect, comparable measurements were carried out with RBCs in a LIS solution with reduced osmolarity ( $200 \mathrm{mM}$ instead of $250 \mathrm{mM}$ sucrose). Under this condition, the cell volume in LIS solution at the beginning of the experiment is about the same like in physiological solution $[1,9]$. As one can see from Fig. 1 no significant difference of the transmembrane potential change can be seen in LIS solution containing 200 $\mathrm{mM}$ sucrose compared with LIS solution containing $250 \mathrm{mM}$ sucrose.

To investigate to what extent the transmembrane potential in LIS solution is changed the CCCP method was used. Experiments were carried out to prove the validity of the method. The results are shown in Fig. 3. In physiological solution (HIS, control experiments) the transmembrane potential was estimated at $-10.2 \pm 2.1 \mathrm{mV}(\mathrm{n}=3)$ for human RBCs. The situation changed when the RBCs were transferred in LIS solution (containing $250 \mathrm{mM}$ sucrose) immediately before the start of the $\mathrm{pH}$ recording. From 6 independent experiments with human RBCs an initial transmembrane potential value of $73.0 \pm 14.5 \mathrm{mV}$ was estimated. The final equilibrium value of $-7.3 \pm 7.4 \mathrm{mV}$ was reached after $65.8 \pm 19.7 \mathrm{~min}(\mathrm{n}=6)$. One representative experiment for human RBC measurements in HIS and LIS solution containing $250 \mathrm{mM}$ sucrose is shown in Fig. 4. The same experiments were carried out in LIS solutions 
Fig. 3. Calibration curves of CCCP method. $200 \mu \mathrm{l}$ of freshly drawn packed RBCs were added to unbuffered physiological solution with various concentrations of $\mathrm{K}^{+}$ (from bottom $7.5 \mathrm{mM}, 35 \mathrm{mM}, 75 \mathrm{mM}$ and $150 \mathrm{mM}$, respectively) in the presence of $20 \mu \mathrm{M}$ of the protonophore CCCP and 10 $\mu \mathrm{M}$ of the chloride conductance inhibitor NS1652. Once membrane potential has been stabilized, the ionophore valinomycin was added, leading to hyperpolarization due to $\mathrm{K}^{+}$efflux, then $\mathrm{V}_{\mathrm{M}}$ tends eventually to $\mathrm{E}_{\mathrm{K}+}$. The membrane potential is plotted against final $\mathrm{K}^{+}$ concentration determined in extracellular solutions by flame photometry (inset, data presented are mean \pm SEM of 3 independent experiments).

Fig. 4. Representative experiment of transmembrane potential estimation of human RBCs in unbuffered solutions in the presence of $20 \mu \mathrm{M}$ of the protonophore CCCP. At time zero, $200 \mu \mathrm{l}$ of packed RBCs were added to $4.8 \mathrm{ml}$ HIS (high ionic strength) solution - lower trace, or LIS (low ionic strength) solution - upper trace and the $\mathrm{pH}$ measured (right axis). Then it was converted into transmembrane potential (left axis, see Methods). At the end of the experiment Triton X-100 was added to determine the intracellular $\mathrm{pH}$.
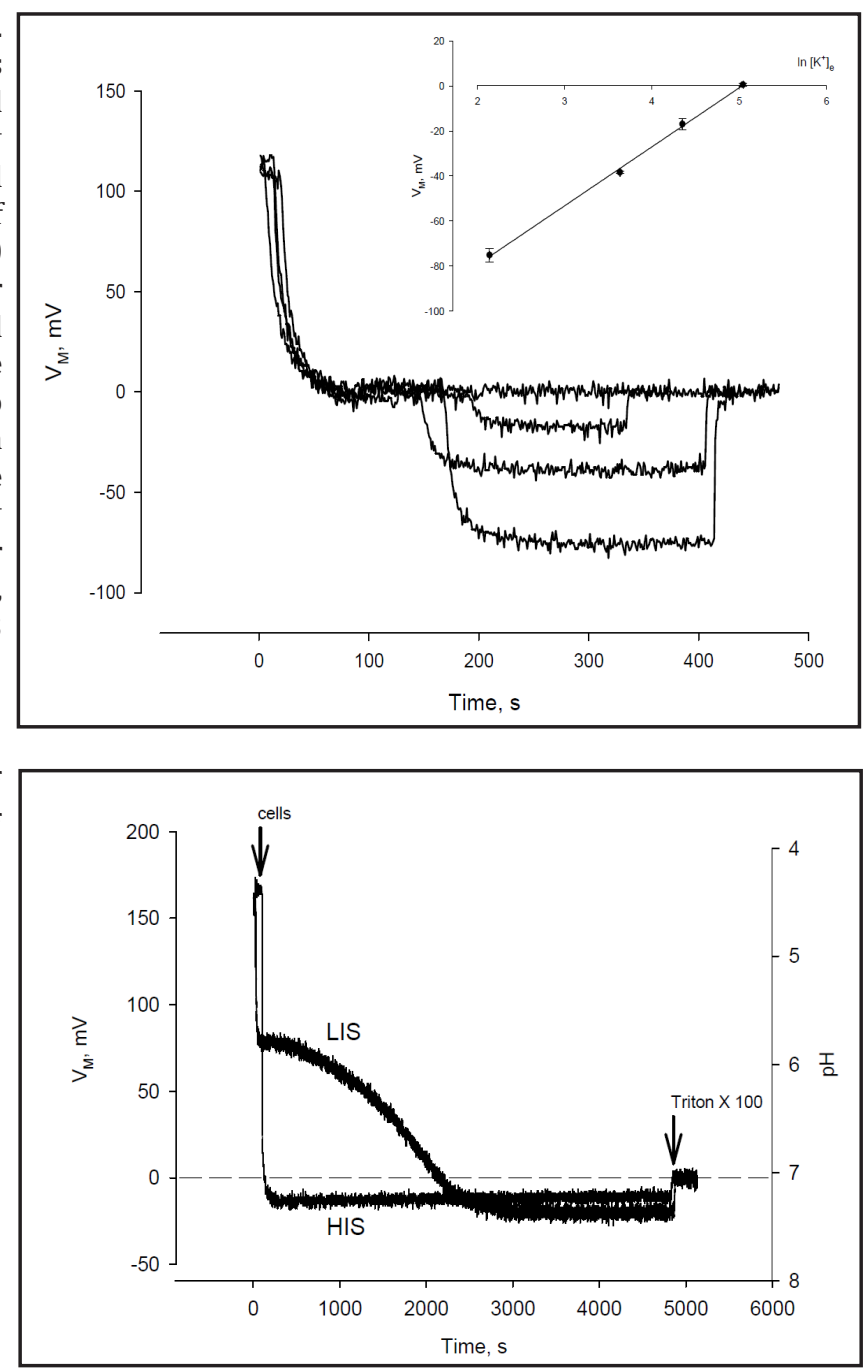

Fig. 5. Representative experiment of transmembrane potential estimation of cow RBCs in unbuffered solutions in the presence of $20 \mu \mathrm{M}$ of the protonophore CCCP. At time zero, $200 \mu \mathrm{l}$ of packed RBCs were added to $4.8 \mathrm{ml}$ HIS (high ionic strength) solution - lower trace, or LIS (low ionic strength) solution - upper trace and the $\mathrm{pH}$ measured (right axis). Then it was converted into transmembrane potential (left axis, see Methods). At the end of the experiment Triton X-100 was added to determine the intracellular $\mathrm{pH}$.

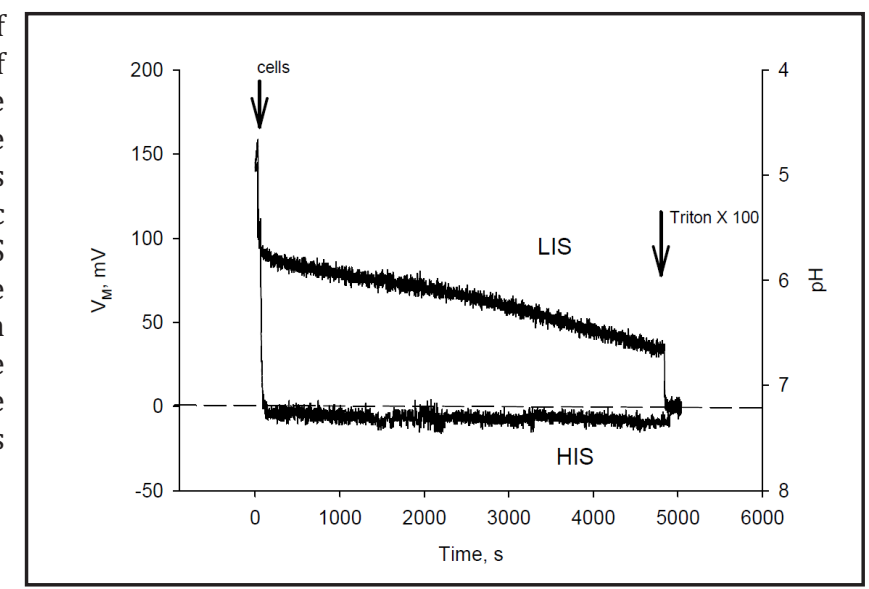

containing $200 \mathrm{mM}$ sucrose (instead of $250 \mathrm{mM}$, see above). The estimated experimental values (initial transmembrane potential $71.3 \pm 4.9 \mathrm{mV}$, equilibrium value $-8.7 \pm 5.2 \mathrm{mV}$, time needed to reach the equilibrium value $59.3 \pm 10.8 \mathrm{~min}, \mathrm{n}=6$ ) did not change significantly.

The CCCP method was also used to determine changes of the transmembrane potential of bovine RBCs. In physiological solution (HIS, control experiments) it was estimated at $-13.2 \pm$ $1.7 \mathrm{mV}(\mathrm{n}=3$ ). In LIS solution (containing $250 \mathrm{mM}$ sucrose) an initial transmembrane potential 
of $80.8 \pm 3.8 \mathrm{mV}(\mathrm{n}=6)$ was estimated. In comparison to human RBCs the transmembrane potential for bovine RBCs declined much more slowly reaching a value of $72.0 \pm 1.2 \mathrm{mV}(\mathrm{n}=$ 6) after $30 \mathrm{~min}$. One representative experiment for bovine RBC measurements in HIS and LIS solution containing $250 \mathrm{mM}$ is shown in Fig. 5.

\section{Discussion}

The principal aim of the present work was to investigate the process of transmembrane potential change of human and bovine RBCs after the cells are transferred into a LIS medium. The transmembrane potential of RBCs of both species is about $-10 \mathrm{mV}$ under physiological conditions (Figs. 1, 4, 5) as expected from literature data [24-26]. It immediately increased to about $+70 \mathrm{mV}$ (for human RBCs) and $+80 \mathrm{mV}$ (for bovine RBCs) after the cells were put into a LIS solution (Figs. 4, 5). This value is close to the $\mathrm{Cl}^{-}$equilibrium value. Taking into consideration for human RBCs an extracellular $\mathrm{KCl}$ concentration of $7.5 \mathrm{mM}$ (see Methods) and an intracellular $\left(\mathrm{Na}^{+}+\mathrm{K}^{+}\right)$and $\mathrm{Cl}^{-}$concentration of $150 \mathrm{mM}$ and $77 \mathrm{mM}$ [19], respectively, a transmembrane potential of $+57 \mathrm{mV}$ can be inferred if a 100 -fold higher membrane permeability for $\mathrm{Cl}^{-}$compared to $\mathrm{Na}^{+}$and $\mathrm{K}^{+}$is assumed (see [1]).

As can be seen from measurements of the fluorescence intensities of the potentialsensitive fluorescent dye $\operatorname{DiBAC}_{4}$ (3) (Fig. 1) as well as from the measurements using the CCCP method (Fig. 4), the new $\mathrm{Cl}^{-}$equilibrium potential value (maximum value) of human RBCs in LIS media immediately starts to decline and reaches its original value at a new equilibrium state in about 30 - $60 \mathrm{~min}$. Such behaviour is in agreement with earlier findings of our group. We were able to demonstrate that the intracellular $\mathrm{pH}$ is increased immediately from 7.2 in physiological solution to about 7.7 after the cells were transferred into a LIS solution followed by a slower process of cell acidification [12]. The time interval of the process of intracellular $\mathrm{pH}$ reduction is comparable with the change of the transmembrane potential (cf. Fig. 1 of the present paper with Fig. 1 in [12]). In addition, it was shown that the $\mathrm{RBCs}$ reduce their intracellular $\mathrm{Cl}^{-}$content by about $70 \%$ within seconds after transferring the cells into a LIS medium [12].

From these findings it is evident that there is no new equilibrium state immediately after the cells are transferred into a LIS medium. For human RBCs it will be reached only after $30-60 \mathrm{~min}$ and the final transmembrane potential will be nearly the same as compared to the situation in physiological solution. The differences in the declining process of the transmembrane potential of RBCs in buffered $\left(\mathrm{DiBAC}_{4}(3)\right.$ experiments) and unbuffered (CCCP method) LIS media can be explained taking into consideration that under unbuffered extracellular conditions the buffer capacity of haemoglobin leads to a slowdown of the $\mathrm{H}^{+}$ transport mediated by the $\mathrm{K}^{+}\left(\mathrm{Na}^{+}\right) / \mathrm{H}^{+}$exchanger.

Since the transmembrane potential of human RBCs is about $+70 \mathrm{mV}$ at the beginning in LIS medium, both the NSVDC channel as well as the $\mathrm{K}^{+}\left(\mathrm{Na}^{+}\right) / \mathrm{H}^{+}$exchanger will be operating. Since the NSVDC channels of RBCs are open only if the transmembrane potential is higher than $+30 \mathrm{mV}[14,15]$, after about $15 \mathrm{~min}$ in LIS medium they will close. Afterwards, i.e. at lower potentials, only the $\mathrm{K}^{+}\left(\mathrm{Na}^{+}\right) / \mathrm{H}^{+}$exchanger will be active.

In contrast to human RBCs the decrease of the transmembrane potential of bovine RBCs after the cells are transferred into a LIS medium is much lower. This is in agreement with earlier findings assuming the absence of the $\mathrm{K}^{+}\left(\mathrm{Na}^{+}\right) / \mathrm{H}^{+}$exchanger in the membrane of bovine RBCs [16]. It was shown that the decrease of the intracellular $\mathrm{pH}$ of bovine RBCs in LIS solution after the maximum is reached declines significantly lower compared to human RBCs [16]. In addition, one has to take into consideration that the intracellular $\mathrm{K}^{+}$concentration of bovine RBCs is different from human once. It was shown that bovine RBCs change from high potassium (HK) type after birth of the animals to low potassium (LK) type as the animals age [27]. The $\mathrm{K}^{+}$content decreases to about $25-30 \mathrm{mM}$ [27]. Later the existence of two types of populations of RBCs of bovine RBCs (LK and HK type) was demonstrated [28]. For 7 different breeds of cattle the majority of the animals are belonging to the LK type ( $90-100 \%$ 
depending on the breed) [29]. To our knowledge, it has never been investigated whether the NSVDC channel is present in bovine RBCs. However, it is evident that because of the low intracellular $\mathrm{K}^{+}$concentration in the majority of bovine RBCs, the $\mathrm{K}^{+}$loss even in the presence of the NSVDC channel in these cells would be much lower compared to human RBCs.

\section{Conclusion}

The transmembrane potential of human and bovine RBCs is continuously decreasing after the maximum value is reached immediately after the cells are transferred in LIS solution. This process is relatively fast for human RBCs and occurs in about $30-60$ min. It is significantly slower for bovine RBCs. After $30 \mathrm{~min}$ the transmembrane potential of bovine RBCs in LIS solution is still at high positive values. Therefore, investigations of parameters of RBCs like shape depending on transmembrane potential (e.g. [17]) cannot be performed with human RBCs in LIS media. This is especially the case if the time of analysis (e.g. microscopic cell counting) is a long-lasting process. Bovine RBCs would be preferential but also in this case it has to be taken into consideration that no constant transmembrane potential is reached after the cells are transferred into a LIS solution.

\section{Acknowledgements}

This work has been supported by a travel grant (PROCOPE) from the German Academic Exchange Service (DAAD) and the French EGIDE PHC project $N^{\circ} 25171 \mathrm{XH}$.

\section{References}

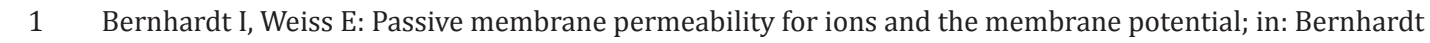
I, Ellory JC (eds): Red cell membrane transport in health and disease. Springer, Berlin, 2003, pp 84-109.

2 Mond R: Umkehr der Anionenpermeabilität der roten Blutkörperchen in eine elektive Durchlässigkeit für Kationen. Ein Beitrag zur Analyse der Zellmembranen. Pflügers Arch 1927;217:618-630.

3 Davson H: Studies on the permeability of erythrocytes. VI. The effect of reducing salt content of the medium surrounding the cell. Biochem J 1939;33:389-401.

4 Wilbrandt W, Schatzmann HJ: Changes in the passive cation permeability of erythro-cytes in low electrolyte media. Ciba Found Study Group 1960;5:34-52.

5 LaCelle PL, Rothstein A: The passive permeability of red blood cells to cations. J Gen Physiol 1966;50:171188.

6 Donlon JA, Rothstein A: The cation permeability of erythrocytes in low ionic strength media of various tonicities. J Membrane Biol 1969;1:37-52.

7 Jones GS, Knauf PA: Mechanism of the increase of the cation permeability of human erythrocytes in lowchloride media. Involvement of the anion transport protein capnophorin. J Gen Physiol 1985;86:721-238.

$>8$ Bernhardt I, Erdmann A, Vogel R, Glaser R: Factors involved in the increase of $\mathrm{K}^{+}$efflux of erythrocytes in low chloride media. Biomed Biochim Acta 1987;46:36-40.

-9 Bernhardt I, Hall AC, Ellory JC: Effects of low ionic strength media on passive human red cell monovalent cation transport. J Physiol 1991;434:489-506.

-10 Bernhardt I, Seidler G, Ihrig I, Erdmann A: Species-dependent differences in the influence of ionic strength on potassium transport of erythrocytes: The role of lipid composition. Gen Physiol Biophys 1992;11:287299.

11 Richter S, Hamann J, Kummerow D, Bernhardt I: The monovalent cation "leak" transport in human erythrocytes: An electroneutral exchange process. Biophys J 1997;73:733-745.

12 Kummerow D, Hamann J, Browning JA, Wilkins R, Ellory JC, Bernhardt I: Variations of intracellular pH in human erythrocytes via $\mathrm{K}^{+}\left(\mathrm{Na}^{+}\right) / \mathrm{H}^{+}$exchange under low ionic strength conditions. J Membrane Biol 2000;176:207-216. 
13 Christophersen P, Bennekou: Evidence for a voltage-gated, non-selective cation channelin the human red cell membrane. Biochim Biophys Acta 1991;1065:103-106.

14 Kaestner L, Bollensdorff C, Bernhardt I: Non-selective voltage-activated cation channel in the human red blood cell membrane. Biochim Biophys Acta 1999;1417:9-15.

15 Kaestner L, Christophersen P, Bernhardt I, Bennekou P: The non-selective voltage-activated cation channel in the human red blood cell membrane: reconciliation between two conflicting reports and further characterisation. Bioelectrochemistry 2000;52:117-125.

-16 Bernhardt I, Weiss E, Robinson HC, Wilkins R, Bennekou P: Differential effect of HOE642 on two separate monovalent cation transporters in the human red cell membrane. Cell Physiol Biochem 2007;20:601-606.

17 Glaser R: The shape of red blood cells as a function of membrane potential and temperature. J Membrane Biol 1979;51:217-228.

18 Erdmann A, Bernhardt I, Herrmann A, Glaser R: Species-dependent differences in the influence of ionic strength on the potassium transport of erythrocytes. Role of membrane fluidity and $\mathrm{Ca}^{2+}$. Gen Physiol Biophys 1990;9:577-588.

19 Hladky SB, Rink TJ: pH equilibrium across the red cell membrane; in: Ellory JC, Lew VL (eds): Membrane transport in red cells. Academic Press, London, 1977, pp 115-135.

20 Macey RI, Adorante JS, Orme FW: Erythrocyte membrane potentials determined by hydrogen ion distribution. Biochm Biophys Acta 1978;5512:284-295.

21 Bennekou P, Christophersen P: Flux ratio of valinomycin-mediated $\mathrm{K}^{+}$fluxes across the human red cell membrane in the presence of the protonophore CCCP. J Membrane Biol 1986;93:221-227.

-22 Bennekou P, Pedersen 0, Møller A, Christophersen P: Volume control in sickle cells is facilitated by the novel anion conductance inhibitor NS1652. Blood 2000;95:1842-1848.

-23 Bennekou P, Barksmann TL, Jensen LR, Kristensen BI, Christophersen P: Voltage activation and hysteresis of the non-selective voltage-dependent channel in the intact human red cell. Bioelectrochem 2004;62:181185.

-24 Lassen UV, Sten-Knudsen O: Direct measurements of membrane potential and membrane resistance of human red cells. J Physiol 1968;195:681-696.

25 Hoffman JF, Laris PC: Determinations of membrane potentials in human and Amphiuma red blood cells by means of a fluorescent probe. J Physiol 1974;239:519-552.

-26 Deutsch CJ, Holian A, Holian SK, Daniele RP, Wilson DF: Transmembrane electrical and pH gradients across human erythrocytes and human peripheral lymphocytes. J Cell Physiol 1979;99:79-93.

27 Israel Y, Macdonald A, Bernstein J, Rosenmann E: Changes from high potassium (HK) to low potassium (LK) in bovine red cells. J Gen Physiol 1972;59:270-284.

28 Ellory JC, Tucker EM: High potassium type red cells in cattle. J Agric Sci 1970;74:595-596.

29 Gonzalez P, Tunon MJ, Vallejo M: Types of red cell potassium in seven Spanish native breeds of cattle. Genet Sel Evol 1988;20:255-258. 